Western University

Scholarship@Western

Chemistry Publications

Chemistry Department

Fall 9-23-2016

\title{
Photocontrolled Degradation of Stimuli- Responsive Poly(ethyl glyoxylate): Differentiating Features and Traceless Ambient Depolymerization
}

Bo Fan

Western University, bfan25@uwo.ca

John Trant

Western University, john.f.trant@gmail.com

Rebecca Yardley

Western University, ryardley@uwo.ca

Andrew Pickering

Western University, a.pickering@mail.utoronto.ca

Francois Lagugne-Labarthet

Western University, flagugne@uwo.ca

See next page for additional authors

Follow this and additional works at: https://ir.lib.uwo.ca/chempub

Part of the Polymer Chemistry Commons

Citation of this paper:

Fan, Bo; Trant, John; Yardley, Rebecca; Pickering, Andrew; Lagugne-Labarthet, Francois; and Gillies, Elizabeth, "Photocontrolled Degradation of Stimuli-Responsive Poly(ethyl glyoxylate): Differentiating Features and Traceless Ambient Depolymerization" (2016). Chemistry Publications. 86.

https://ir.lib.uwo.ca/chempub/86 
Authors

Bo Fan, John Trant, Rebecca Yardley, Andrew Pickering, Francois Lagugne-Labarthet, and Elizabeth Gillies 


\section{Photocontrolled degradation of stimuli-responsive poly(ethyl \\ glyoxylate): Differentiating features and traceless ambient}

\section{depolymerization}

Bo Fan, ${ }^{\dagger}$ John F. Trant, ${ }^{\star}$ Rebecca E. Yardley, ${ }^{\ddagger}$ Andrew J. Pickering, ${ }^{\dagger}$ François LagugnéLabarthet ${ }^{\sharp}$ and Elizabeth R. Gillies ${ }^{\dagger * *}$

'Department of Chemical and Biochemical Engineering, The University of Western Ontario, 1151 Richmond St., London, Ontario, Canada, N6A 5B9

"Department of Chemistry, The University of Western Ontario, 1151 Richmond St., London, Ontario, Canada, N6A 5B7

* Author to whom correspondence should be addressed; E-mail: egillie@uwo.ca 


\section{for Table of Contents use only}

Photocontrolled degradation of stimuli-responsive poly(ethyl glyoxylate): Differentiating features and traceless ambient depolymerization

Bo Fan, John F. Trant, Rebecca E. Yardley, Andrew J. Pickering, François Lagugné-Labarthet and Elizabeth R. Gillies*

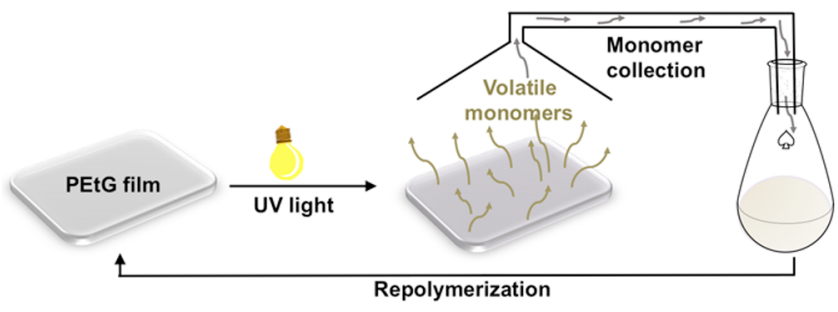




\begin{abstract}
The depolymerization of coatings prepared from a 6-nitroveratryl carbonate end-capped poly(ethyl glyoxylate) (PEtG) self-immolative polymer was studied. This polymer undergoes end-to-end depolymerization following cleavage of the end-cap by UV light. Several important fundamental differences between this class of polymers and conventional degradable polymers were revealed. For example, polymer backbone cleavage and depolymerization exhibited different dependencies on $\mathrm{pH}$, emphasizing the decoupling of these processes. Probing of the coating erosion mechanism illustrated an interesting combination of features from surface erosion and bulk degradation mechanisms that arise from the end-to-end depolymerization mechanism and further differentiate these polymers from convention degradable polymers. It was also demonstrated that unlike backbone cleavage, PEtG depolymerization did not exhibit a dependence on water, and that PEtG could depolymerize back to the volatile monomer ethyl glyoxylate at ambient temperature and pressure. This unusual feature was utilized to perform facile polymer reprogramming/recycling via an irradiation-trapping-repolymerization sequence as well as polymer patterning by a simple irradiation-evaporation sequence.
\end{abstract}

\title{
Introduction
}

In recent years, there has been increasing interest in the development of degradable polymers for a wide range of applications from packaging to biomedical devices. ${ }^{1-3}$ At present, polyesters are widely used, as they can be broken down to nontoxic products. ${ }^{4,5}$ However, their degradation cannot be easily controlled, as random backbone scission occurs gradually in a wide range of environments, and cannot be turned on or off as desired for a given application. To address this limitation, significant efforts have been directed towards the development of stimuli-responsive 
polymers. Polymers responsive to light, ${ }^{6,7}$ heat, ${ }^{8}$ changes in $\mathrm{pH}^{9}$ and many other stimuli have been developed. ${ }^{10,11}$ These polymers require many stimuli-mediated events to completely degrade the polymer backbones. While they perform well in the laboratory, where large changes in conditions can easily be introduced, the gradient of conditions and the concentrations of stimuli in real environments are typically much smaller, presenting a challenge.

To address the above limitations, molecules that depolymerize from end-to-end in response to the cleavage of stimuli-responsive end-caps from the polymer termini, were developed. ${ }^{12,13}$ These polymers, often referred to as "self-immolative polymers" (SIPs), afford amplification of stimuli-mediated events as an entire polymer chain can degrade in response to a single end-cap cleavage. In addition, because of their end-to-end depolymerization mechanism, they exhibit predictable depolymerization times that are dependent on their length and backbone composition. $^{14}$ Backbones including polycarbamates, ${ }^{15-18}$ polycarbonates, ${ }^{19}$ polyethers, ${ }^{20}$ polyphthalaldehydes, ${ }^{21,22}$ and polyglyoxylates ${ }^{23}$ have been synthesized and studied over the last several years and end-caps responsive to stimuli including light, ${ }^{24}$ heat, ${ }^{25}$ fluoride ions, ${ }^{26}$ redox change, ${ }^{16,27}$ enzymes, ${ }^{28}$ and mechanical force ${ }^{29}$ have been reported. The unique features of these polymers have made them attractive for potential applications in molecular sensors, ${ }^{15,30}$ responsive films, ${ }^{31,32}$ micropumps, ${ }^{26}$ drug delivery systems, ${ }^{17,24}$ and microcapsules. ${ }^{33,34}$

Polyglyoxylates are an attractive class of polymers that can undergo depolymerization upon end-cap cleavage due to their low ceiling temperatures $\left(\mathrm{T}_{\mathrm{c}}\right){ }^{23}$ Glyoxylate monomers such as ethyl glyoxylate (EtG) are commercially available or can be prepared from readily available starting materials such as maleic or fumaric acid. ${ }^{23}$ In addition, they ultimately degrade to glyoxylic acid, ${ }^{35-37}$ a metabolite found in some mammalian biochemical pathways ${ }^{38}$ and an intermediate in the glyoxylate cycle, an anaerobic variant of the tricarboxylic acid cycle that 
occurs in plants, bacteria, protists, and fungi. ${ }^{37}$ Here we explore in detail the degradation of endcapped self-immolative poly(ethyl glyoxylate) (PEtG). In particular, the solid-state degradation of PEtG demonstrates several important novel and unusual aspects of the end-to-end depolymerization and also reveals that upon end-cap cleavage, PEtG undergoes depolymerization under ambient conditions to afford volatile products. This offers new opportunities for one-step traceless patterning and for simple polymer recycling or reprogramming.

\section{Experimental section}

General procedures and materials. All chemicals were purchased from commercial suppliers and used without further purification unless otherwise noted. $\mathrm{Et}_{3} \mathrm{~N}$ and $\mathrm{CH}_{2} \mathrm{Cl}_{2}$ were distilled from calcium hydride before use. 6-Nitroveratryl carbonate end-capped PEtG (PEtG-NVOC) and benzyl carbonate end-capped PEtG were prepared as previously reported. ${ }^{23}$ PEtG-NVOC used in the current studies had a number average molar mass $\left(\mathrm{M}_{\mathrm{n}}\right)$ of $35 \mathrm{~kg} / \mathrm{mol}$ and a dispersity $(\nexists)$ of 1.4. The benzyl carbonate end-capped PEtG had an $\mathrm{M}_{\mathrm{n}}$ of $42 \mathrm{~kg} / \mathrm{mol}$ and a $Ð$ of 1.4 . Characterization data for these specific batches are included in Figures S1-S6. The soil was standard potting soil from Premier Tech (Rivière-du-Loup, Canada). Nylon bags were made from a nylon 6/6 woven mesh sheet with $80 \mu \mathrm{m}$ mesh size purchased from Small Parts, Inc. (Logansport, IN, USA). The size exclusion chromatography (SEC) instrument was equipped with a Viscotek GPC Max VE2001 solvent module (Malvern Instruments Ltd., Malvern, UK). Samples were analyzed using the Viscotek VE3580 RI detector operating at $30{ }^{\circ} \mathrm{C}$. The separation technique employed two Agilent Polypore $(300 \times 7.5 \mathrm{~mm})$ columns connected in series and to a Polypore guard column $(50 \times 7.5 \mathrm{~mm})$ (Agilent Technologies, Santa Clara, CA, USA). 
Samples were dissolved in tetrahydrofuran (THF) (glass distilled grade) at a concentration of approximately $5 \mathrm{mg} / \mathrm{mL}$ and filtered through $0.22 \mu \mathrm{m}$ syringe filters, then injected using a 100 $\mu \mathrm{L}$ loop. The THF eluent was filtered and eluted at $1 \mathrm{~mL} / \mathrm{min}$ for a total of 30 minutes. A calibration curve was obtained from poly(methyl methacrylate) standards with molar masses from 1540-1126000 g/mol (Agilent Technologies, Santa Clara, CA, USA). ${ }^{1} \mathrm{H}$ NMR spectra were obtained at $600 \mathrm{MHz}$ on a Varian Inova instrument (Varian, Palo Alto, CA, USA). The scanning electron microscopy (SEM) images of polymer films were taken on a Hitachi S-3400N instrument at a voltage of $2 \mathrm{kV}$ (Hitachi, Tokyo, Japan). The samples were mounted on carbontaped aluminum stubs and sputtered with gold at a rate of $5 \mathrm{~nm} / \mathrm{min}$ for 4 minutes (Hummer-6 sputtering system, Anatech, Union City, CA, USA).

Preparation of PEtG coatings. $\mathrm{PEtG}$ was dissolved in $\mathrm{CH}_{2} \mathrm{Cl}_{2}$ at a concentration of $90 \mathrm{mg} / \mathrm{mL}$. This solution was drop-cast onto glass microscope slides and the solvent was evaporated in vacuo for $48 \mathrm{~h}$ to afford coatings. The coating thickness was measured using a caliper. $330 \mu \mathrm{L}$ cast over $2 \mathrm{~cm}^{2}$ afforded a thickness of $\sim 150 \mu \mathrm{m}$. For thinner coatings, $1 \mathrm{~mL}$ of $30 \mathrm{mg} / \mathrm{mL}$ polymer solution cast over $6 \mathrm{~cm}^{2}$ afforded $\sim 50 \mu \mathrm{m}$, or $2 \mathrm{~mL}$ of $15 \mathrm{mg} / \mathrm{mL}$ polymer solution cast over $12 \mathrm{~cm}^{2}$ afforded $\sim 25 \mu \mathrm{m}$. Each coating had a total mass of $\sim 30 \mathrm{mg}$.

\section{Degradation studies of PEtG films in aqueous buffer solutions at varying $\mathrm{pH}$ and} temperature. The initial masses of coatings were measured and recorded. Irradiated coatings were placed into an ACE Glass photochemistry cabinet containing a mercury light source (450 W bulb, $2.8 \mathrm{~mW} / \mathrm{cm}^{2}$ measured for UVA radiation at the sample position) for $5 \mathrm{~h}$ to cleave the NVOC end-cap. A coating of PEtG with a benzyl carbonate (non-photo-responsive end-cap) was 
also irradiated to verify that the polymer backbone was stable to UV irradiation and that it was specifically the NVOC end-cap that was susceptible to cleavage by UV light (Figure S7). Nonirradiated coatings were stored in the dark. Next, all of the slides ( 3 per time point, per condition) were immersed into a $0.1 \mathrm{M}$ aqueous buffer solution (citrate buffer for $\mathrm{pH} 5.0$; phosphate buffer for $\mathrm{pH} 6.0,7.0$ and 8.0 ) at a given temperature. $10{ }^{\circ} \mathrm{C}$ was obtained by placing the samples into a refrigerator set to this temperature. $20^{\circ} \mathrm{C}$ corresponded to ambient temperature of a temperaturecontrolled room. In this case, protection from light was afforded by storing the samples in a cabinet. $30^{\circ} \mathrm{C}$ was obtained by placing samples into an oven set to this temperature. At selected times, 3 coatings from each treatment were removed from the buffer solution, rinsed with distilled water, dried under house vacuum for $48 \mathrm{~h}$, and then weighed. The percent of initial mass of the coating at a given time point was calculated as (mass at time point/initial mass) x $100 \%$. In each case, the error bars correspond to the standard deviation of the measurements of 3 different samples. At $\mathrm{pH} 7.0$ and $20^{\circ} \mathrm{C}$, the samples were also analyzed by SEC, samples at $\mathrm{t}=0$ and $\mathrm{t}=5$ days were analyzed by SEM, and the residual coatings at selected time points were dissolved in $\mathrm{CDCl}_{3}$ and ${ }^{1} \mathrm{H}$ NMR spectra were obtained (Figures S8-S11).

Degradation of PEtG coatings in soil with varying water content. The soil was autoclaved, dried in an oven $\left(120^{\circ} \mathrm{C}\right)$, and weighed. The soil was then used dry or rehydrated with $0.1 \mathrm{M} \mathrm{pH}$ 7.0 phosphate buffer to 10,20 , or 30 mass percent. The irradiated and non-irradiated coatings with a thickness of $150 \mu \mathrm{m}$ were prepared as described above for the studies in buffer except that instead of immersing the coatings into buffer solution, they were placed into nylon bags, and immersed in soil ( $350 \mathrm{~g}$ dry soil per 30 slides). The box was sealed to prevent the evaporation of water. At different time points, the nylon bags were removed from the soil, and both the slides 
and nylon bags were washed with $\mathrm{CH}_{2} \mathrm{Cl}_{2}$, filtered and the solvent was evaporated. The remaining material was weighed to determine the mass of remaining polymer and the percent of initial mass of the coating was calculated as described above. Error bars correspond to the standard deviation of the measurements of 3 different samples.

Degradation of PEtG coatings in air. Coatings were prepared and weighed as described above. Irradiated coatings were placed into the photochemistry cabinet described above for $4 \mathrm{~h}$ to remove the end-cap. During this time the non-irradiated coatings were stored in the dark. All coatings were then stored at either $20^{\circ} \mathrm{C}$ (ambient, thermostat-controlled) or at $30{ }^{\circ} \mathrm{C}$ (oven). Protection from light was afforded by storing samples in either a cabinet or the oven. At selected time points, the masses of the slides were measured and then the slides were returned to their depolymerization conditions. The percent of initial mass of the coating was calculated as described above. Error bars correspond to the standard deviation on the measurements of 3 different samples.

Sunlight-triggered coating degradation. Coatings were prepared and weighed as described above. All coatings were then placed in a greenhouse, with half protected from sunlight with aluminum foil, and the other half exposed to sunlight through the greenhouse glass. The temperature of the environment varied over the experiment from approximately 9 to $37^{\circ} \mathrm{C}$ over the day-night cycle in a Southwestern Ontario, Canada, Spring (May-June). At selected time points, the masses of the slides were measured and then they were returned to their depolymerization conditions. The percent of initial mass of the coating remaining was calculated 
as described above. Error bars correspond to the standard deviation of on the measurements of 3 different samples.

Collection of depolymerized ethyl glyoxylate monomer. $600 \mathrm{mg}$ of PEtG-NVOC was dissolved in $5.0 \mathrm{~mL}$ of $\mathrm{CH}_{2} \mathrm{Cl}_{2}$, then the $\mathrm{CH}_{2} \mathrm{Cl}_{2}$ was evaporated in vacuo to coat the walls of a round bottom flask (A). Then the polymer film was dried under high vacuum. Flask A was then placed in the photochemistry cabinet described above for 4 hours. It was then immersed in an oil bath at $50{ }^{\circ} \mathrm{C}$, and connected to a vacuum (240 mTorr) and to Flask B, which was cooled in a liquid nitrogen bath to trap the volatile ethyl glyoxylate depolymerization product (Figure S13). The mass of flask B was measured every 1 or 2 hours over a period of 9 hours to determine the mass of collected ethyl glyoxylate. The identity of the collected product was determined by ${ }^{1} \mathrm{H}$ NMR spectroscopy to be ethyl glyoxylate, by comparison with the known spectrum of the commercial product (Figure S14). A control experiment was also performed under identical conditions but without UV irradiation. No conversion to liquid monomer was observed and no monomer transferred to the collection flask.

Repolymerization of collected monomer. The collected ethyl glyoxylate $(0.5 \mathrm{~g}, 5 \mathrm{mmol}, 1.0$ equiv.) was dissolved in $\mathrm{CH}_{2} \mathrm{Cl}_{2}(0.5 \mathrm{~mL})$ and $\mathrm{Et}_{3} \mathrm{~N}(0.35 \mu \mathrm{L}, 2.5 \mu \mathrm{mol}, 0.0005$ equiv. $)$ was added. The solution was stirred for $1 \mathrm{~h}$ at $-20{ }^{\circ} \mathrm{C}$. 6-Nitrovertryloxycarbonyl chloride (NVOC-Cl) (22 mg, $73 \mu \mathrm{mol}, 0.014$ equiv.) and $\mathrm{Et}_{3} \mathrm{~N}\left(10 \mu \mathrm{L}, 73 \mu \mathrm{mol}, 0.014\right.$ equiv.) were then added at $0{ }^{\circ} \mathrm{C}$ to end-cap the polymer. The solution was stirred for $24 \mathrm{~h}$ at room temperature. Purification was achieved by dialysis against $1: 1$ acetone: methanol using a regenerated cellulose membrane with a molecular weight cut-off of $2000 \mathrm{~g} / \mathrm{mol}$. The yield was $12 \%$. This is an unoptimized yield as 
the aim of the experiment was to demonstrate proof of principle. It is likely low as the polymer has a low $\mathrm{M}_{\mathrm{n}}$, making the standard precipitation procedure impossible and much material was likely lost through the dialysis. It can likely be improved through optimization of the set-up (such as decreasing exposure of the ethyl glyoxylate to air during the weighing procedure that was used to generate Figure 3) and also certainly through distillation of the recycled ethyl glyoxylate if required (high purity is very important for achieving high degrees of polymerization). ${ }^{1} \mathrm{H}$ NMR $\left(600 \mathrm{MHz}, \mathrm{CDCl}_{3}\right): \delta$ 7.69-7.76 (m, 2H), 7.12-7.21 (m, 2H), 5.46-5.78 (m, 18H), 4.10-4.33 (m, $32 \mathrm{H}), 4.00-4.06(\mathrm{~m}, 6 \mathrm{H}), 3.94-3.98(\mathrm{~m}, 6 \mathrm{H}), 1.21-1.44(\mathrm{~m}, 50 \mathrm{H}) . \mathrm{SEC}: \mathrm{M}_{\mathrm{n}}=1.7 \mathrm{~kg} / \mathrm{mol}, \mathrm{M}_{\mathrm{w}}=$ $2.8 \mathrm{~kg} / \mathrm{mol}, Ð=1.6$.

Pattern fabrication. For Figure 4c, PEtG-NVOC (15 mg) was dissolved in $\mathrm{CH}_{2} \mathrm{Cl}_{2}(1 \mathrm{~mL})$ and was drop-cast onto a glass slide over a surface area of $6.6 \mathrm{~cm}^{2}$ to provide a $\sim 20 \mu \mathrm{m}$-thick film. For Figure 4d, PEtG-NVOC (100 mg) was dissolved in $\mathrm{CH}_{2} \mathrm{Cl}_{2}(4 \mathrm{~mL})$ and $1 \mathrm{~mL}$ was spincoated onto a glass slide over a surface area of $20 \mathrm{~cm}^{2}$ to provide a $13 \mu \mathrm{m}$-thick film. After the solvent was evaporated in vacuo for $48 \mathrm{~h}$, the coatings were covered with metal mask patterns shown in Fig. 3a and 3b, for the $20 \mu \mathrm{m}$ and the $13 \mu \mathrm{m}$-thick coatings respectively. The mask with $500 \mu \mathrm{m}$ diameter holes was a meshed aluminum grid while the mask with $20 \mu \mathrm{m}$ diameter holes was a chromium mask engraved over a borosilicate glass. Irradiation through the masks was performed using a mask-aligner (Neutronix-Quintel NXQ 4006) to ensure spatial uniformity of the irradiation. The thinner film was irradiated during 0.5 hour while the thicker film was irradiated for 1 hour using an irradiance of $35 \mathrm{~mW} / \mathrm{cm}^{2}$ from a mercury light source. After the irradiation, the films were stored in the dark at ambient temperature $\left(\sim 20{ }^{\circ} \mathrm{C}\right)$ for 6 days. The 
images of polymer patterns were taken on an optical microscope (Zeiss Axioskop2 MAT Microscope equipped with 1300 CCD Digital Camera) on the $6^{\text {th }}$ day after irradiation.

\section{Results and discussion}

PEtG with a UV light-sensitive 6-nitroveratryl carbonate end-cap (PEtG-NVOC) was synthesized as previously reported via the low temperature polymerization of EtG, following by end-capping with 6-nitroveratryl chloroformate. ${ }^{23}$ Irradiation of PEtG-NVOC with UV light results in cleavage of the NVOC moiety from the polymer terminus (Scheme 1). This is followed by decarboxylation, revealing hemiacetal-terminated PEtG, which undergoes depolymerization. In the presence of water, the resulting ethyl glyoxylate (EtG) is rapidly converted to ethyl glyoxylate hydrate (EtGH), then gradually hydrolyzed to glyoxylic acid hydrate and ethanol. ${ }^{23}$ It was previously demonstrated that the degradation of PEtG by backbone cleavage in the absence of UV light was much slower than UV-triggered depolymerization and that UV irradiation of PEtG with a non-responsive benzyl carbonate end-cap did not lead to degradation. ${ }^{23}$ For the current study, unless otherwise indicated, coatings of PEtG-NVOC were prepared by dropcasting the polymer onto glass slides to provide coatings $\sim 150 \mu \mathrm{m}$ thick. Samples treated with UV light were irradiated with a mercury lamp having an intensity of $\sim 2.8 \mathrm{~mW} / \mathrm{cm}^{2}$ in the UVA range. Control coatings were kept in the dark. The slides were then immersed in aqueous solution. At each time point, irradiated and control films were removed from the solution, rinsed, dried, and their masses were measured. As the polymers are insoluble in water beyond the oligomer form and the films remained intact and adhered to the glass slides until greater than $90 \%$ mass loss had occurred, this measurement provided a good indication of the extent of depolymerization that had occurred. 


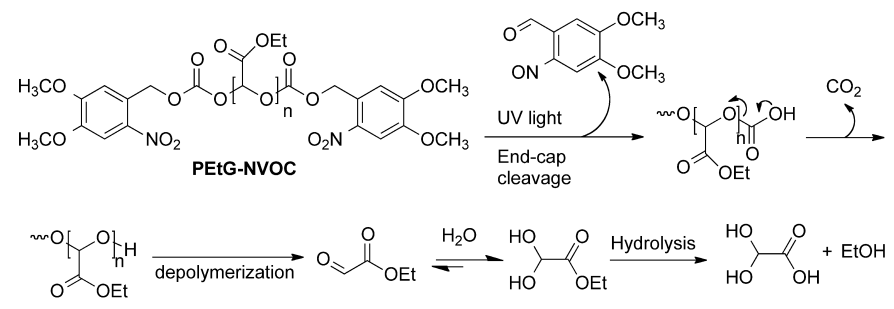

Scheme 1. Chemical structure of PEtG-NVOC and its UV light-initiated depolymerization. This is followed by hydrate formation and hydrolysis of the resulting ethyl glyoxylate in the presence of water.

To investigate the effect of $\mathrm{pH}$, coatings were immersed in buffer solutions of $\mathrm{pH} 3-8$ and stored at $20{ }^{\circ} \mathrm{C}$. As shown in Figure 1a, at $\mathrm{pH} 6-8$ the irradiated coatings behaved similarly, eroding to $\sim 50 \%$ of their initial mass over 5 days. At $\mathrm{pH} 5$, the erosion of the irradiated polymer was significantly slower, requiring more than 20 days to reach $50 \%$ mass loss. Then, at $\mathrm{pH} 3-4$ the erosion again became more rapid, reaching a rate intermediate between that of $\mathrm{pH} 5$ and $\mathrm{pH} 6$ -8 . This highlights the first key difference between the end-to-end depolymerization and random backbone cleavage mechanism for polyglyoxylates. Random backbone cleavage of PEtG would involve the hydrolysis of an acetal linkage. This is well known to be an acid-catalyzed process, with a rate directly dependent on the concentration of $\mathrm{H}^{+}$(Scheme S1). ${ }^{39}$ Based on the stability of the non-irradiated control coatings, this reaction is very slow at $20{ }^{\circ} \mathrm{C}$ from $\mathrm{pH} 3-8$. This can likely be attributed to the electron-withdrawing ester moiety, which would destabilize the adjacent carbocation intermediate involved in the hydrolysis mechanism. On the other hand, endto-end depolymerization of the triggered PEtG involves the sequential breakdown of terminal hemiacetals. In aqueous solution, hemiacetal hydrolysis can be catalyzed by acid (Scheme S2) or base (Scheme S3). ${ }^{40,41}$ It has been reported that hemiacetal decomposition is generally faster 
than acetal decomposition and that a rate minimum for hemiacetal cleavage occurs at mildly acidic $\mathrm{pH}^{40,41}$ Both of these observations are consistent with the results of the current study, where more rapid mass loss was observed for the irradiated polymer coatings at all $\mathrm{pHs}$, and a minimum rate of mass loss was observed at $\mathrm{pH} 5$. Overall, these differences in mechanisms and rates between of the backbone cleavage and end-to-end depolymerization demonstrate an effective decoupling of these processes.
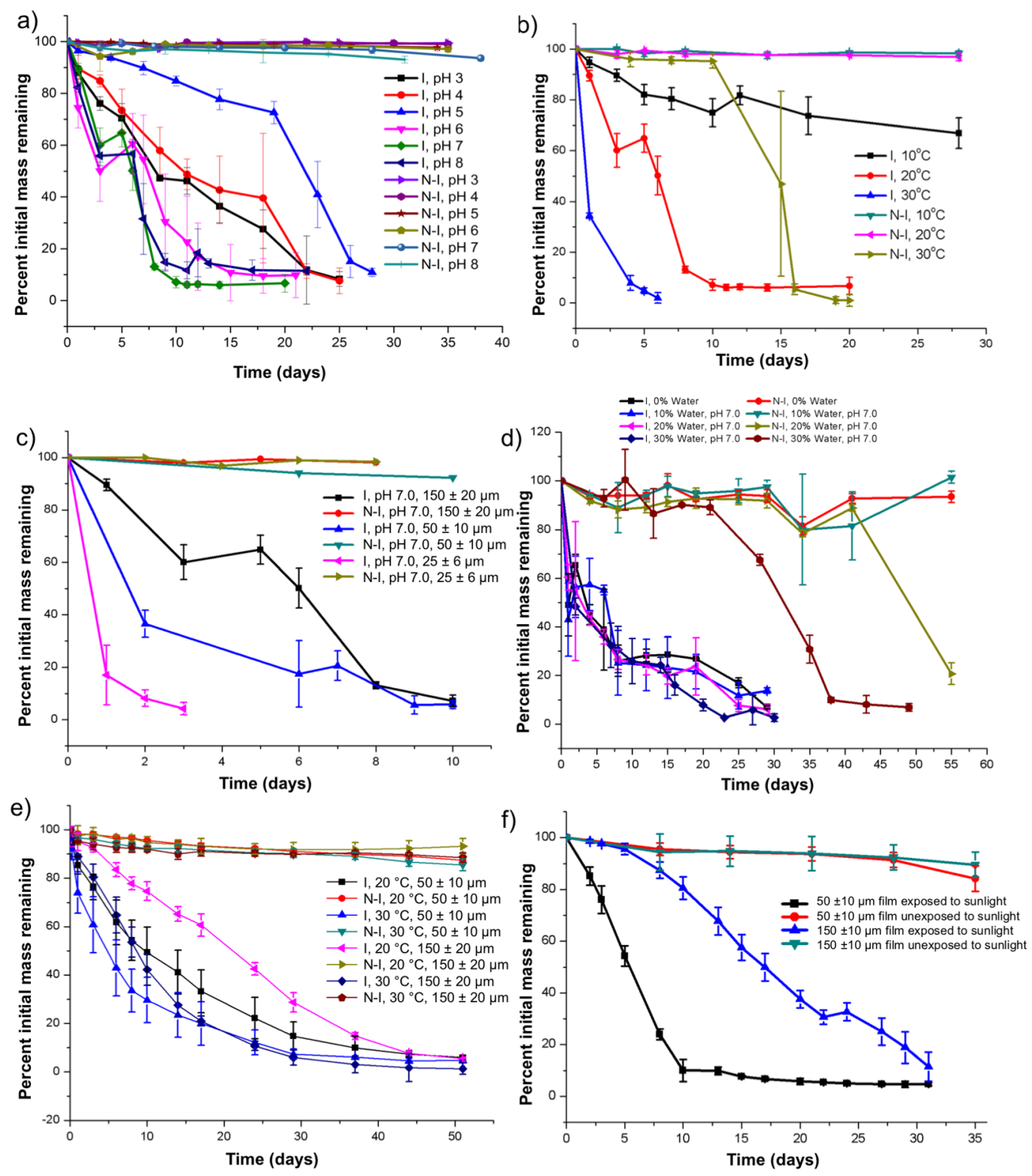
Figure 1. Mass loss profiles for UV light irradiated (I) and non-irradiated (N-I) PEtG-NVOC coatings under different conditions: (a) $150 \mu \mathrm{m}$ thickness immersed at $20^{\circ} \mathrm{C}$ in buffers of pH $3-$ 8; (b) $150 \mu \mathrm{m}$ thickness immersed at varying temperatures in $\mathrm{pH} 7.0$ buffer; (c) Varying film thicknesses from $25-150 \mu \mathrm{m}$ immersed in $\mathrm{pH} 7.0$ buffer at $20^{\circ} \mathrm{C}$; (d) $150 \mu \mathrm{m}$ thickness immersed in soil with either 10,20 or 30 mass \% of pH 7.0 buffer at $20^{\circ} \mathrm{C}$; (e) Film thicknesses of 50 or $150 \mu \mathrm{m}$ in air (no aqueous immersion) at either 20 or $30^{\circ} \mathrm{C}$; (f) Film thicknesses of 50 or $150 \mu \mathrm{m}$ in air either exposed or not exposed to sunlight in a greenhouse. In each experiment, the error bars represent the standard deviation of the measurements for three samples.

The effect of temperature on the depolymerization rate was also explored by incubating irradiated and non-irradiated coatings in $\mathrm{pH} 7$ buffer at temperatures of 10,20 , or $30{ }^{\circ} \mathrm{C}$. As expected on the basis of kinetics as well as entropic contributions to $\Delta \mathrm{G}$, temperature had a significant effect on the rate of coating erosion, with the irradiated coating at $30{ }^{\circ} \mathrm{C}$ requiring less than 1 day for $50 \%$ mass loss while more than 28 days was required at $10{ }^{\circ} \mathrm{C}$ (Figure $1 \mathrm{~b}$ ). The non-irradiated coatings were stable at $10{ }^{\circ} \mathrm{C}$ and $20{ }^{\circ} \mathrm{C}$ while at $30{ }^{\circ} \mathrm{C}$ degradation began at $\sim 12$ days. At this temperature the rate of backbone cleavage reactions in the presence of water becomes sufficient to cleave chains and initiate depolymerization.

A notable and unusual feature of the mass loss profiles in Figure 1a-b was a distinct plateau or even increase at $\sim 40 \%$ mass loss. We hypothesized that this was related to the surface accessibility of the polymers and resulting depolymerization products. It was proposed that the apparent mass increase might have arisen from the production and temporary trapping of EtGH as depolymerization occurred and water slowly penetrated into the coating, subsequently reacting to form this hydrate within the coating. Indeed ${ }^{1} \mathrm{H}$ NMR spectra of the residual coating material 


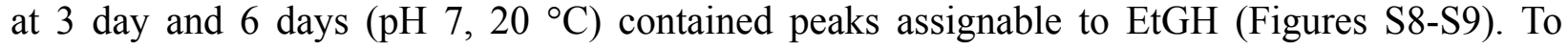
further evaluate this phenomenon, coatings of different thicknesses were prepared and studied. As shown in Figure 1c, the plateau for a $\sim 50 \mu \mathrm{m}$ thick coating was at $\sim 80 \%$ mass loss while no plateau was observed for an even thinner film of $\sim 25 \mu \mathrm{m}$. This confirms that accessibility of depolymerizing polymers to the coating surface is indeed important for coating erosion. This can likely be attributed to the fact that released EtG can potentially re-add to the polymer terminus if it is not rapidly released from the coating or trapped by water to form the hydrate. This presents an opportunity to tune the coating erosion time by simply changing the coating thickness for various applications. It should be noted however that upon increasing the coating thickness to $300 \mu \mathrm{m}$, the mass loss did not proceed beyond $\sim 60 \%$ (Figure S12). This presumably results from incomplete end-cap cleavage due to the inability of sufficient UV light to penetrate these thicker coatings using our experimental set-up. ${ }^{1} \mathrm{H}$ NMR spectra of the $150 \mu \mathrm{m}$-thick coatings did not show any end-cap, confirming complete cleavage (Figures S8-S9), whereas intact end-cap could be clearly observed for non-irradiated coatings (Figure S10-S11).

Conditions of $\mathrm{pH} 7.0$ and $20{ }^{\circ} \mathrm{C}$ and a coating thickness of $150 \mu \mathrm{m}$ were selected to further probe the erosion mechanism. Water-insoluble degradable polymers can undergo surface erosion or bulk erosion. Which process dominates for a given polymer is generally dependent on the relative rates of bond cleavage, diffusion of water into the polymer and the dimensions of a given polymer specimen. ${ }^{42}$ As shown in Figure 1a-c, the degradation profiles for the irradiated polymers suggest a surface erosion process, as mass loss began immediately. This was supported by minimal changes in the molar mass characteristics of the bulk polymer as determined by size exclusion chromatography (Figure 2a). The initial small drop in $\mathrm{M}_{\mathrm{n}}$ can likely be attributed to 
some depolymerization that occurred in the THF SEC solvent after sample dissolution of each of the irradiated samples as depolymerization can occur slowly in THF.

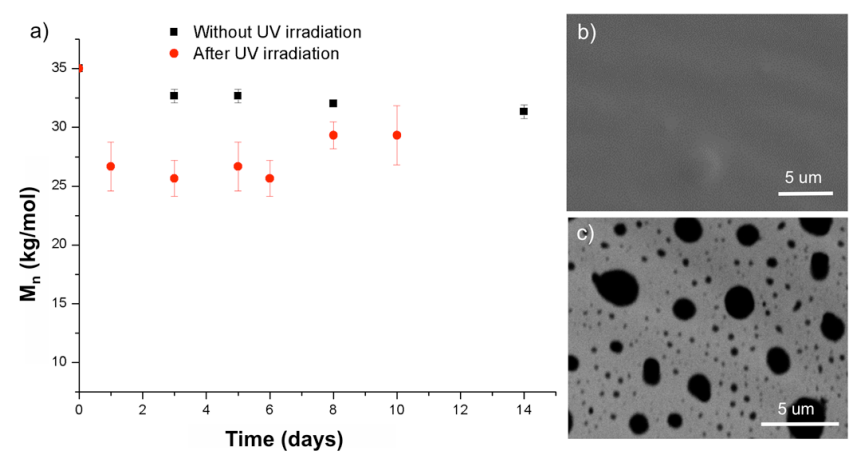

Figure 2. (a) Number average molar mass $\left(\mathrm{M}_{\mathrm{n}}\right)$ of polymer remaining on the coating during the mass loss study, as measured by SEC.; (b,c) SEM images of the polymer coating after 5 days of immersion in $0.1 \mathrm{M}, \mathrm{pH} 7.0$ phosphate buffer at $20^{\circ} \mathrm{C}(\mathrm{b})$ control without UV irradiation and (c) with UV irradiation.

The surfaces were also imaged by SEM. The non-irradiated coating retained a smooth and intact surface (Figure 2b) while the irradiated coating developed holes (Figure 2c). The smooth appearance of these surfaces can be attributed to the amorphous nature and low $\mathrm{T}_{\mathrm{g}}\left(-9^{\circ} \mathrm{C}\right)$ of PEtG. ${ }^{23}$ The surface erosion mechanism can be explained by the rapid decomposition of hemiacetals, combined with the importance of surface accessibility for diffusion of the depolymerization products out of the coating. In contrast, the delayed mass loss of the nonirradiated coating is more characteristic of a bulk degradation mechanism, where water diffuses through the polymer, resulting in slow bond cleavage. ${ }^{42}$ In this case bond cleavage would involve slow, non-specific hydrolysis of the polymer backbone. However, unlike polyesters such as poly(lactic acid) that commonly undergo bulk erosion, ${ }^{43}$ non-irradiated PEtG does not undergo 
changes in molar mass prior to the onset of mass loss (Figure 2a). Polyesters can undergo multiple bond cleavages in the polymer backbone throughout the bulk polymer matrix prior to the loss of mass, as shorter polymer chains remain insoluble. In contrast, even a non-irradiated PEtG undergoes complete backbone depolymerization to water-soluble small molecules following a single backbone scission event. This highlights another key difference between the end-to-end depolymerization mechanism of PEtG and the random backbone hydrolysis that occurs in conventional degradable polymers.

It was also of interest to investigate the erosion of PEtG in the natural environment, so mass loss was investigated in soil-like conditions with varying water content (Figure 1d). A significant dependence on the water content was observed for the non-irradiated coatings. This can be attributed to the requirement for water to participate in any cleavage reaction of the end-capped polymer, including ester, acetal, or carbonate hydrolysis. On the other hand, the erosion rate of irradiated coatings exhibited no significant dependence on water, suggesting that water was not required for end-to-end depolymerization. This led to the discovery that irradiated PEtG coatings readily depolymerized under ambient conditions with the depolymerization time dependent on temperature and coating thickness (Figure 1e). In the absence of water, the polymer matrix is presumed to serve as a proton transfer agent and EtG is the final degradation product (Scheme S4). Having a boiling point of $110^{\circ} \mathrm{C}$, similar to toluene, it readily evaporates from the surface. No plateau in the mass loss was observed in these studies, consistent with the above explanation relating to the trapping of EtGH in coatings that were immersed in aqueous conditions. It was also found that sunlight could trigger depolymerization under ambient conditions resulting in a coating erosion time that was dependent on its thickness (Figure 1f). This thickness dependence can arise from the decreased penetration of the light through the thicker coating and also from 
the inherent dependence of the coating depolymerization time on thickness that was observed in Figure 1c and e. Combined, these data demonstrate that solid-state PEtG-NVOC has the ability to degrade in an essentially traceless manner under ambient conditions in response to a specific external stimulus and that the coating depolymerization time can be tuned by adjusting parameters such as coating thickness.

The depolymerization of polymers back to volatile monomers under ambient conditions is very rare. "Traceless" depolymerization has been reported using poly(vinyl sulfone)s (PVS) and it has been shown that these polymers undergo depolymerization in the presence of ionizing radiation, UV light, heat, or mechanical force. ${ }^{44-48}$ However, a key limitation is that the overall stability of PVS is directly correlated with their susceptibility to undergo depolymerization as it is backbone cleavage itself that triggers depolymerization. Consequently, their inherent instability may limit their application. In contrast, end-to-end depolymerization of PEtG is initiated by end-cap cleavage and this is triggered by different stimuli and conditions than backbone cleavage, as demonstrated above. Effectively, the end-cap affords a removable barrier to the otherwise thermodynamically favorable depolymerization process, allowing the polymer to be utilized above its inherent ceiling temperature. Among the other backbones that undergo end-to-end depolymerization, polyphthalaldehyde has also been demonstrated to depolymerize in the solid state. $^{21,22}$ However, the $o$-phthalaldehyde depolymerization product is a solid at room temperature with a melting point of $55-58{ }^{\circ} \mathrm{C}$ and a boiling point of $266^{\circ} \mathrm{C}$. High vacuum is required to volatilize it, making the recollection of monomer difficult, and it tends to sublime rather than distill.

To demonstrate the proof-of-concept for a potential application of the unusual behavior of PEtG-NVOC, a full cycle of material degradation and regeneration at the molecular level was 
performed. PEtG-NVOC was irradiated with UV light, and then moderate heating $\left(50^{\circ} \mathrm{C}\right)$ and modest vacuum (240 mTorr) were used to accelerate the depolymerization and transfer of EtG monomer to a second flask (Figure 3). More than $85 \%$ of the material could be collected over less than $10 \mathrm{~h}$ and the identity of the product was confirmed to be ethyl glyoxylate by ${ }^{1} \mathrm{H}$ NMR spectroscopy (Figure S14). Without further processing, this monomer could be repolymerized and end-capped to afford again PEtG-NVOC (Figure S15-S16). In contrast, applying the same conditions without UV irradiation did not result in any conversion of the polymer to liquid monomer and no monomer was transferred to the collection flask, confirming the end-capped polymer's stability under the experimental conditions.

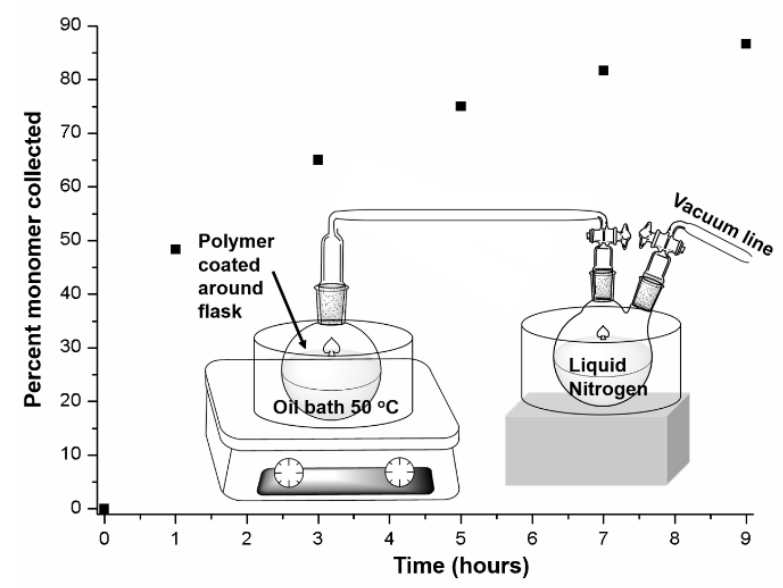

Figure 3. Collection of depolymerized ethyl glyoxylate monomer over time after irradiation of PEtG-NVOC and the corresponding experimental set-up.

Recently, depolymerization as a means of potentially recycling polymers has been a topic of increasing interest. For example, it was shown that polycarbonates that were prepared from epoxides and $\mathrm{CO}_{2}$ could be depolymerized in solution to either their monomers or cyclic carbonates depending on the particular polymer backbone and the depolymerization conditions. $^{49-51}$ It was also recently demonstrated that poly( $\gamma$-butyrolactone) could be 
depolymerized to monomers due to the thermodynamically favorable generation of the 5membered lactone ring. ${ }^{52}$ However, high temperatures of $220{ }^{\circ} \mathrm{C}$ and $300{ }^{\circ} \mathrm{C}$ were required to achieve depolymerization for the linear and cyclic forms of the polymer respectively. Poly(aromatic ester)s derived from benzodioxepinones were also found to undergo reversible polymerization and depolymerization using $\mathrm{Al}$ catalysts in solution depending on the temperature and concentration of the material..$^{53}$ Furthermore, poly(benzyl ether)s could be selectively depolymerized in the presence of polystyrene or polypropylene and then the monomers could be selectively dissolved, purified by extraction, and then repolymerized. ${ }^{54}$ To the best of our knowledge, in comparison with PEtG, there is no other polymer that has been depolymerized and repolymerized through such a simple process under mild conditions.

To further demonstrate the utility of the ambient depolymerization, PEtG-NVOC was investigated as a material for traceless one-step patterning. Metal masks with $500 \mu \mathrm{m}$ or $20 \mu \mathrm{m}$ holes were placed over PEtG-NVOC films and they were then irradiated with UV light. Over a period of 6 days, the corresponding features appeared in the polymer films without any further intervention or treatment under ambient conditions. Shown in Figure 4 are the masks and the optical images of the resulting microscale features. The irradiated areas show holes while the integrity of the surrounding thin film is preserved. These results highlight the possibility of using such an approach for micro or nanofabrication processes. All photopolymers used for standardized micro- (UV lithography) and nano-scale (electron beam lithography) production require a wet chemical processing step for both the developing and lift off steps. With our approach we envision the possibility of reducing the use of developing chemicals for lithography processes. Nevertheless, further work will be needed to investigate and optimize the aspect ratio of the obtained structures and their compatibility with other microfabrication steps. In addition, it 
would be ideal to increase the rate of pattern formation. This might be achieved by increasing the temperature or using a more volatile glyoxylate such as methyl glyoxylate.

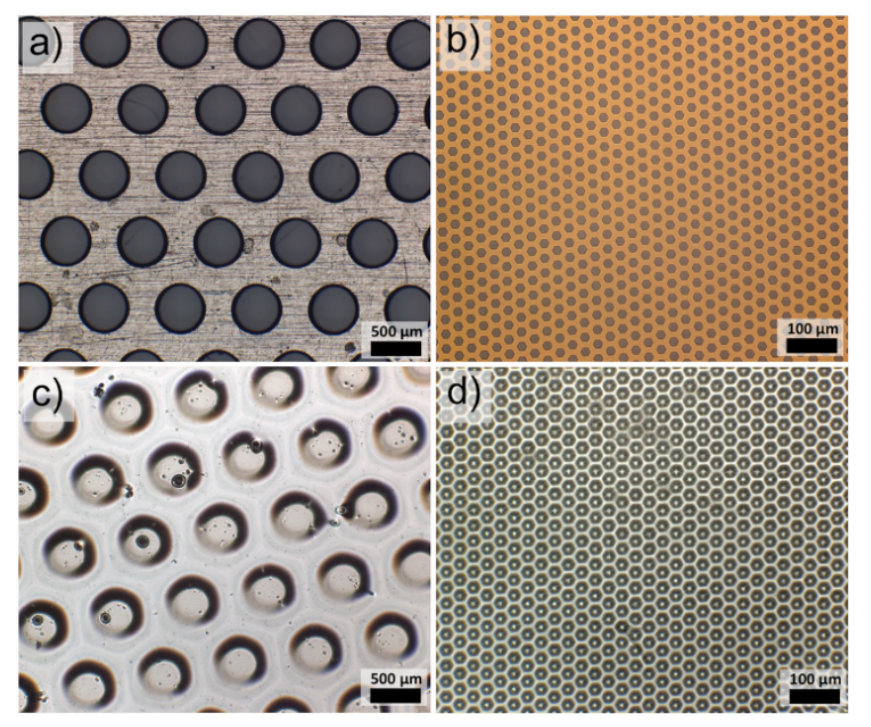

Figure 4. Digital optical microscopy of ambient self-developed patterns: The metal masks are shown in (a) and (b) while the corresponding $500 \mu \mathrm{m}$ and $20 \mu \mathrm{m}$ reservoirs fabricated from these masks are shown in (c) and (d) respectively.

\section{Conclusions}

In conclusion, this study of PEtG depolymerization in the solid state has demonstrated several unique features of PEtG depolymerization that clearly differentiate it from conventional polymer degradation processes. Through studies of the $\mathrm{pH}$ dependence, it was shown that the mildly acidic conditions that accelerate backbone cleavage of conventional polyacetals actually slow the depolymerization process as the hemiacetals cleave more readily under neutral conditions. It was also shown that the rapid end-to-end depolymerization combined with the surface erosion mechanism results in an unusual plateau in the mass loss, while the transfer of degradation products out of the film catch up with depolymerization. In addition, while the time required for depolymerization depended in a predictable way on temperature and coating thickness, it was not 
dependent on water, leading to the discovery that after end-cap cleavage, PEtG exhibits a rare ability to undergo depolymerization to volatile products under ambient temperature and pressure. This was demonstrated to offer unique capabilities for the direct reprogramming or recycling of polymers under mild conditions as well as for the preparation of self-developing patternable coatings.

\section{Supporting information}

${ }^{1} \mathrm{H}$ and ${ }^{13} \mathrm{C}$ NMR spectra of polymers, SEC data, proposed depolymerization mechanisms, additional degradation data, monomer collection and repolymerization set-up. This material is available free of charge via the Internet at http://pubs.acs.org.

\section{Acknowledgements}

The authors thank the Natural Sciences and Engineering Research Council of Canada (DG to ERG and FLL; SPG to ERG; fellowships to REY and AJP) and the University of Western Ontario (WIF grant to ERG) for funding this research. The authors acknowledge the Western Nanofabrication Facility for the photopatterning experiments and the Ragogna group for use of their photochemical reactor.

\section{References}

(1) Tschan, M. J.-L.; Brulé, E.; Haquette, P.; Thomas, C. M. Synthesis of Biodegradable Polymers from Renewable Resources. Polym. Chem. 2012, 3, 836-851. 
(2) Hwang, S.-W.; Song, J.-K.; Huang, X.; Cheng, H.; Kang, S.-K.; Kim, B.-H.; Kim, J.-H.; Yu, S.; Huang, Y.; Rogers, J. A. High-Performance Biodegradable/Transient Electronics on Biodegradable Polymers. Adv. Mater. 2014, 26, 3905-3911.

(3) Delplace, V.; Nicolas, J. Degradable Vinyl Polymers for Biomedical Applications. Nat. Chem. 2015, 7, 771-784.

(4) Tian, H.; Tang, Z.; Zhuang, X.; Chen, X.; Jing, X. Biodegradable Synthetic Polymers: Preparation, Functionalization and Biomedical Application. Prog. Polym. Sci. 2012, 37, 237-280.

(5) Yin, Q.; Yin, L.; Wang, H.; Cheng, J. Synthesis and Biomedical Applications of Functional Poly (A-Hydroxy Acids) Via Ring-Opening Polymerization of O-Carboxyanhydrides. Acc. Chem. Res. 2015, 48, 1777-1787.

(6) Rwei, A. Y.; Wang, W.; Kohane, D. S. Photoresponsive Nanoparticles for Drug Delivery. Nano Today 2015, 10, 451-467.

(7) Gohy, J.-F.; Zhao, Y. Photo-Responsive Block Copolymer Micelles: Design and Behavior. Chem. Soc. Rev. 2013, 42, 7117.

(8) Roy, D.; Brooks, W. L.; Summerlin, B. S. New Directions in Thermoresponsive Polymers. Chem. Soc. Rev. 2013, 42, 7214-7243.

(9) Binauld, S.; Stenzel, M. H. Acid-Degradable Polymers for Drug Delivery: A Decade of Innovation. Chem. Commun. 2013, 49, 2082-2012.

(10) Cohen Stuart, M.; Huck, W. T. S.; Genzer, J.; Muller, M.; Ober, C.; Stamm, M.; Sukhorukov, G. B.; Szieifer, I.; Trukruk, V. V.; Urban, M.; Winnik, F.; Zauscher, S.; Luzinov, I.; Minko, S. Emerging Applications of Stimuli-Responsive Polymer Materials. Nat. Mater. 2010, 9, 101-113. 
(11) Schattling, P.; Florian, D. J.; Theato, P. Multi-Stimuli Responsive Polymers-the All-inOne Talents. Polym. Chem. 2014, 5, 25-36.

(12) Wong, A. D.; DeWit, M. A.; Gillies, E. R. Amplified Release through the Stimulus Triggered Degradation of Self-Immolative Oligomers, Dendrimers, and Linear Polymers. Adv. Drug Delivery Rev. 2012, 64, 1031-1045.

(13) Phillips, S. T.; DiLauro, A. M. Continuous Head-to-Tail Depolymerization: An Emerging Concept for Imparting Amplified Responses to Stimuli-Responsive Materials. ACS Macro Lett. 2014, 3, 298-304.

(14) McBride, R. A.; Gillies, E. R. Kinetics of Self-Immolative Degradation in a Linear Polymeric System: Demonstrating the Effect of Chain Length. Macromolecules 2013, 46, 51575166.

(15) Sagi, A.; Weinstain, R.; Karton, N.; Shabat, D. Self-Immolative Polymers. J. Am. Chem. Soc. 2008, 130, 5434-5435.

(16) DeWit, M. A.; Beaton, A.; Gillies, E. R. A Reduction Sensitive Cascade Biodegradable Linear Polymer. J. Polym. Sci. Part A: Polym. Chem. 2010, 48, 3977-3985.

(17) Liu, G.; Wang, X.; Hu, J.; Zhang, G.; Liu, S. Self-Immolative Polymersomes for HighEfficiency Triggered Release and Programmed Enzymatic Reactions. J. Am. Chem. Soc. 2014, $136,7492-7497$.

(18) Liu, G.; Zhang, G.; Hu, J.; Wang, X.; Zhu, M.; Liu, S. Hyperbranched Self-Immolative Polymers (HSIPS) for Programmed Payload Delivery and Ultrasensitive Detection. J. Am. Chem. Soc. 2015, 137, 11645-11655. 
(19) Chen, E. K. Y.; McBride, R. A.; Gillies, E. R. Self-Immolative Polymers Containing Rapidly Cyclizing Spacers: Toward Rapid Depolymerization Rates. Macromolecules 2012, 45, 7364-7374.

(20) Olah, M. G.; Robbins, J. S.; Baker, M. S.; Phillips, S. T. End-Capped Poly(Benzyl Ethers): Acid and Base Stable Polymers That Depolymerize Rapidly from Head-to-Tail in Response to Specific Applied Signals. Macromolecules 2013, 46, 5924-5928.

(21) DiLauro, A. M.; Robbins, J. S.; Phillips, S. T. Reproducible and Scalable Synthesis of End-Cap-Functionalized Depolymerizable Poly(Phthalaldehydes). Macromolecules 2013, 46, 2963-2968.

DiLauro, A. M.; Lewis, G. G.; Phillips, S. T. Self-Immolative Poly(4,5Dichlorophthalaldehyde) and Its Applications in Multi-Stimuli-Responsive Macroscopic Plastics. Angew. Chem. Int. Ed. 2015, 127, 6298-6303.

(23) Fan, B.; Trant, J. F.; Wong, A. D.; Gillies, E. R. Polyglyoxylates: A Versatile Class of Triggerable Self-Immolative Polymers from Readily Accessible Monomers. J. Am. Chem. Soc. 2014, 136, 10116-10123.

(24) de Gracia Lux, C.; L. McFearin, C.; Joshi-Barr, S.; Sankaranarayanan, J; Fomina N, Almutairi, A. A Single Uv or near Ir Triggering Event Leads to Polymer Degradation into Small Molecules. ACS Macro Lett. 2012, 1, 922-926.

(25) Peterson, G. I.; Church, D. C.; , N. A. Y.; Boydston, A. J. 1,2-Oxazine Linker as a Thermal Trigger for Self-Immolative Polymers. Polymer 2014, 09, 048.

(26) Zhang, H.; Yeung, K.; Robbins, J. S.; Pavlick, R. A.; Wu, M.; Liu, R.; Sen, A.; Phillips, S. T. Self-Powered Microscale Pumps Based on Analyte-Initiated Depolymerization Reactions. Angew. Chem. Int. Ed. 2012, 51, 2400-2404. 
(27) Wong, A. D.; Güngör, T. M.; Gillies, E. R. Multiresponsive Azobenzene End-Cap for SelfImmolative Polymers. ACS Macro Letters 2014, 3, 1191-1195.

(28) Weinstain, R.; Sagi, A.; Karton, N.; Shabat, D. Self-Immolative Comb-Polymers: Multiple-Release of Side-Reporters by a Single Stimulus Event. Chem. Eur. J. 2008, 14, 68576861.

(29) Diesendruck, C. E.; Peterson, G. I.; Kulik, H. J.; Kaitz, J. A.; Mar, B. D.; May, P. A.; White, S. R.; Martinez, T. J.; Boydston, A. J.; Moore, J. S. Mechanically Triggered Heterolytic Unzipping of a Low-Ceiling-Temperature Polymer. Nat. Chem. 2014, 6, 623-628.

(30) Lewis, G. G.; Robbins, J. S.; Phillips, S. T. Phase-Switching Depolymerizable Poly(Carbamate) Oligomers for Signal Amplification in Quantitative Time-Based Assays. Macromolecules 2013, 46, 5177-5183.

(31) Mohapatra, M.; Kim, H.; Phillips, S. T. Stimuli-Responsive Polymer Film That Autonomously Translates a Molecular Detection Event into a Macroscopic Change in Its Optical Properties Via a Continuous, Thiol-Mediated Self-Propagating Reaction. J. Am. Chem. Soc. 2015, 137, 12498-12501.

(32) Kim, H.; Mohapatra, H.; Phillips, S. T. Rapid, On-Command Debonding of StimuliResponsive Cross-Linked Adhesives by Continuous, Sequential Quinone Methide Elimination Reactions. Angew. Chem. Int. Ed. 2015, 54, 13063-13067.

(33) Esser-Kahn, A. P.; Sottos, N. R.; White, S. R.; Moore, J. S. Programmable Microcapsules from Self-Immolative Polymers. J. Am. Chem. Soc. 2010, 132, 10266-10268.

(34) DiLauro, A. M.; Abbaspourrad, A.; Weitz, D. A.; Phillips, S. T. Stimuli-Responsive CoreShell Microcapsules with Tunable Rates of Release by Using a Depolymerizable Poly(Phthalaldehyde) Membrane. Macromolecules 2013, 46, 3309-3313. 
(35) Brachais;, C. H.; Huguet;, J.; Bunel;, C.; Brachais, L. In Vitro Degradation of Poly(Methyl Glyoxylate) in Water. Polymer 1998, 39, 883-890.

(36) Belloncle, B.; Burel, F.; Bunel, C. Synthesis and (Bio)degradation of Poly(Ethyl Glyoxylate). Polym. Prepr. 2007, 48, 633-634.

(37) Belloncle, B.; Burel, F.; Oulyadi H.; Bunel, C. Study of the In Vitro Degradation of Poly(Ethyl Glyoxylate). Polym. Deg. Stab. 2008, 93, 1151-1157.

(38) Funai, T.; Ichiyama, A. High-Performance Liquid Chromatographic Determination of Glyoxylate in Rat Liver J. Biochem. 1986, 99, 579-589.

(39) Fife, T.; Jao, L. Substituent Effects in Acetal Hydrolysis. J. Org. Chem. 1965, 30, 14921495.

(40) Przystas, T. J.; Fife, T. H. The Mechanism of Hemiacetal Decomposition. Substituent Effects in Breakdown of Substituted Benzaldehyde Ethyl Hemiacetals. J. Am. Chem. Soc. 1981, 103, 4884-4890.

(41) Funderburk, L. H.; Aldwin, L.; Jencks, W. P. Mechanisms of General Acid and Base Catalysis of the Reactions of Water and Alcohols with Formaldehyde. J. Am. Chem. Soc. 1978, $100,5444-5459$.

(42) von Burkersroda, F.; Schedl, L.; Göpferich, A. Why Degradable Polymers Undergo Surface Erosion or Bulk Erosion. Biomaterials 2002, 23, 4221-4231.

(43) Göpferich, A. Polymer Bulk Erosion. Macromolecules 1997, 30, 2598-2604.

(44) Bowden, M. J.; O’Donnell, J. H. Developments in Polymer Degradation, Elsevier: Barking, 1985; Vol. 6, p 21-61. 
(45) Jiang, Y.; Fréchet, J. M. J. Design and Synthesis of Thermally Labile Polymers for Microelectronics. Poly(Vinyl tert-Butyl Carbonate-Sulfone). Macromolecules 1991, 24, 35283532.

(46) Lobez, J. M.; Swager, T. M. Radiation Detection: Resistivity in Functional Poly(Olefin Sulfone)/Carbon Nanotube Composites. Angew. Chem. Int. Ed. 2010, 49, 95-98.

(47) Lee, O. P.; Hernandez, H. L.; Moore, J. S. Tunable Thermal Degradation of Poly(Vinyl Butyl Carbonate Sulfone)S Via Side Chain Branching. ACS Macro Lett. 2015, 4, 665-668.

(48) Kumar, K.; Goodwin, A. P. Alternating Sulfone Copolymers That Depolymerize in Response to Both Chemical and Mechanical Stimuli. . ACS Macro Lett. 2015, 4, 907-911.

(49) Darensbourg, D. J.; Wei, S.-H. Depolymerization of Polycarbonates Derived from Carbon Dioxide and Epoxides to Provide Cyclic Carbonates. A Kinetic Study. Macromolecules 2012, $45,5916-5922$.

(50) Darensbourg, D. J.; Wei, S.-H.; Yeung, A. D.; Ellis, W. C. An Efficient Method of Depolymerization of Poly(Cyclopentene Carbonate) to Its Comonomers: Cyclopentene Oxide and Carbon Dioxide. Macromolecules 2013, 46, 5850-5855.

(51) Darensbourg, D. J.; Yeung, A. D.; Wei, S.-H. Base Initiated Depolymerization of Polycarbonates to Epoxide and Carbon Dioxide Co-Monomers: A Computational Study. Green Chem. 2013, 15, 1578-1583.

(52) Hong, M.; Chen, E. Y.-X. Completely Recyclable Biopolymers with Linear and Cyclic Topologies Via Ring-Opening Polymerization of $\gamma$-Butyrolactone. Nat. Chem. 2016, 8, 42-49.

(53) MacDonald, J. P.; Shaver, M. P. An Aromatic/Aliphatic Polyester Prepared Via RingOpening Polymerisation and Its Remarkably Selective and Cycable Depolymerisation to Monomer. Polym. Chem. 2016, 7, 553-559. 
(54) Baker, M. S.; Kim, H.; Olah, M. G.; Lewis, G. G.; Phillips, S. T. Depolymerizable Poly(Benzyl Ether)-Based Materials for Selective Room Temperature Recycling. Green Chem. 2015, 17, 4541-4545. 